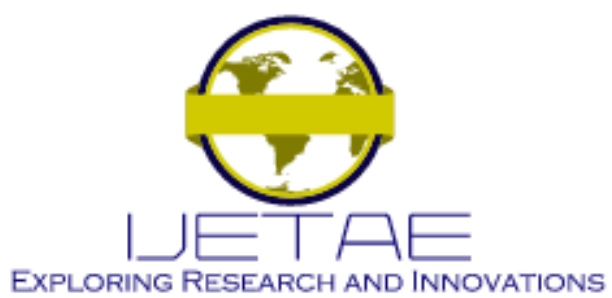

International Journal of Emerging Technology and Advanced Engineering

Website: www.ijetae.com (E-ISSN 2250-2459, Scopus Indexed, ISO 9001:2008 Certified Journal, Volume 11, Issue 10, October 2021)

Manuscript Received: 04 September 2021, Received in Revised form: 09 October 2021, Accepted: 14 October 2021

DOI: $10.46338 /$ ijetae1021_14

\title{
Electrical Appliance Switching Controller by Brain Wave Spectrum Evaluation Using a Wireless EEG Headset
}

\author{
Abd Gani, S. F. ${ }^{1}$, Miskon, M. F. ${ }^{2}$, Hamzah, R. A. ${ }^{3}$, A. Aziz, K. A. ${ }^{4}$, Kadmin, A. F. ${ }^{5}$, Jidin, A. Z. ${ }^{6}$, Md Basar, M. F. ${ }^{7}$, \\ Kamalrudin, M. ${ }^{8}$, A. Razak, E. N. S. ${ }^{9}$, Md Ali Shah, M. A. S. ${ }^{10}$ \\ ${ }^{1,3,4,5,6,7,9}$ Fakulti Teknologi Kejuruteraan Elektrik dan Elektronik, Universiti Teknikal Malaysia Melaka, Malaysia \\ ${ }^{2}$ Fakulti Kejuruteraan Elektrik, Universiti Teknikal Malaysia Melaka, Malaysia \\ ${ }^{8}$ Fakulti Teknologi Maklumat dan Komunikasi, Universiti Teknikal Malaysia Melaka, Malaysia \\ ${ }^{10}$ MASH Construction Engineering Services Sdn. Bhd., Malaysia
}

\begin{abstract}
Disabled people are usually unable to interact with their surroundings efficiently, and performing tasks like switching an appliance on or off can be troublesome if the user is bedridden, for example. This article discusses an electrical appliance switching controller using a wireless EEG headset that is aimed to aid elderly people and the disabled. The system comprises of a MindLink EEG headset that is Bluetooth-connected to an Arduino microcontroller board. The system permits the user to separately switch on and off the 4 electrical devices connected to the power socket. The EEG signal is obtained to investigate the brain activity throughout the experiments done. Based on the brain wave signals read, attention and meditation are determined to be the most suitable for this project and is used to trigger the relay switching of the power socket. It is found that the response time to trigger the switching is slow as some users require practice or training to control their brain wave signals effectively. The work performed provides a rudimentary insight of a BCI system functionalities and presents a brainwave-controlled hardware switching for the bedridden or disabled patients.
\end{abstract}

Keywords - electroencephalography, EEG, smart home, brain computer interface, BCI application.

\section{INTRODUCTION}

The World Health Organization (WHO) asserts that roughly $15 \%$ of people in the world lives with certain type of a disability [1]. Individuals with disabilities, for the most part, are incapable to interact with their surroundings to speak with others, move, or control appliances and tools. This limits their freedom, forcing them to rely on others to perform simple activities like turning on and off lights and fans, which can lead to frustration, dissatisfaction, or even depression. Their life can be greatly improved if they can have the freedom to control the things they need with minimal dependence to other people.
These individuals may be unable to use their limbs, but are capable of thinking, so it is promising to investigate and understand their electroencephalogram (EEG) brain signals for translating their needs. The goal of this project is to make it easier for handicapped or bedridden individuals to manage household appliances wirelessly and without having to use their hands. Instead of hard-coding the smart controller into every different appliance that the user has, this project aims to create a universal appliance controller by embedding the said controller into a power socket instead. This power socket can then be connected to whatever electrical appliance the user desires, enabling the user to do more than just control lights and fans. The proposed system consists of a MindLink EEG headset neuro sensor which is Bluetooth-connected to an Arduino microcontroller board. During the experiment, the EEG signal is used to study the brain's activity, and the triggering element is calculated and applied to meet the project's best case scenario. The technology allows the user to turn on and off each of the 4 electrical items attached to the power outlet separately using only his or her brain signal.

\section{LITERATURE REVIEW}

There are many interaction methods and interfaces between machines and humans. Keyboards, mice, and joysticks are examples of common human-machine interfaces for receiving input. A few biological signal sensors such as electromyogram (EMG) and electroencephalogram (EEG) have recently been utilized as hands-free machine interfaces. The brain-computer interface (BCI) especially has garnered a lot of interest among researchers recently. The $\mathrm{BCI}$ is a technology that collects and analyses neural (brain) signals in order to establish a direct high-bandwidth communication link between the brain and the computer [2]. 


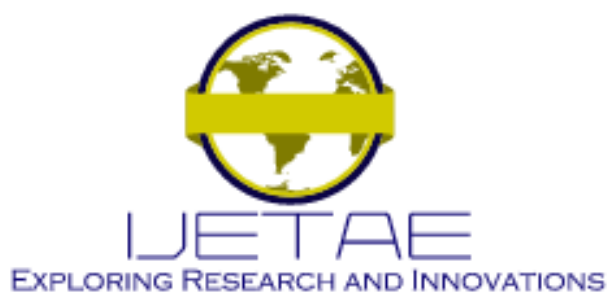

International Journal of Emerging Technology and Advanced Engineering

Website: www.ijetae.com (E-ISSN 2250-2459, Scopus Indexed, ISO 9001:2008 Certified Journal, Volume 11, Issue 10, October 2021)

Education, production, marketing, security, and entertainment are just a few of the fields where brain signal reading and remote communication have made an influence [3]-[5]. Figure 1 illustrates the comparison between various non-invasive and invasive brain computer interface (BCI) technology that is presently available [6], [7] where in the latter, an IC is surgically placed inside the brain, which is why non-invasive $\mathrm{BCI}$, which just requires the use of a headset or a cap with active electrode system, is preferred [8].

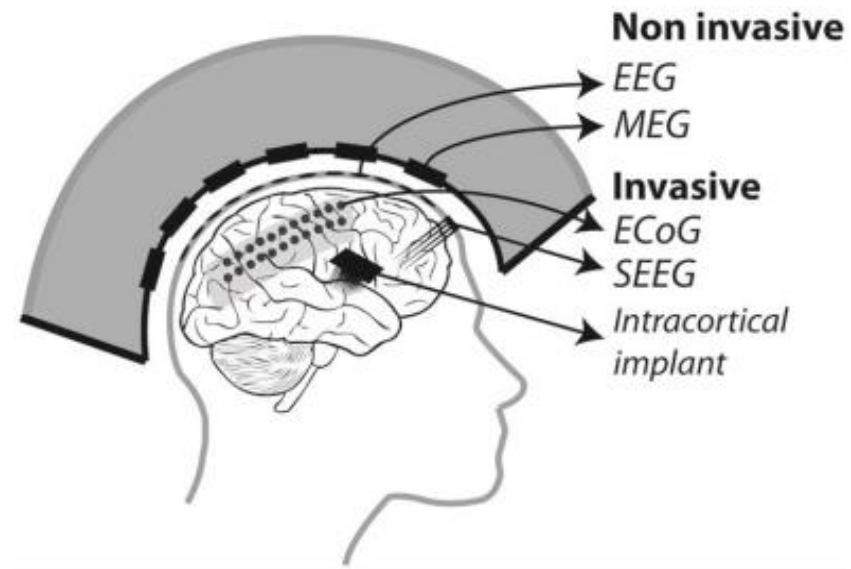

Figure 1. Comparison between non-invasive and invasive BCI.

EEG became the popular and preferable non-invasive BCI method because it is cheap, simple, quick response, and its ability to be implemented with portable products [9], [10]. EEG plays a significant part in healthcare systems, and it is widely utilised in the diagnosis of illnesses involving the brain.

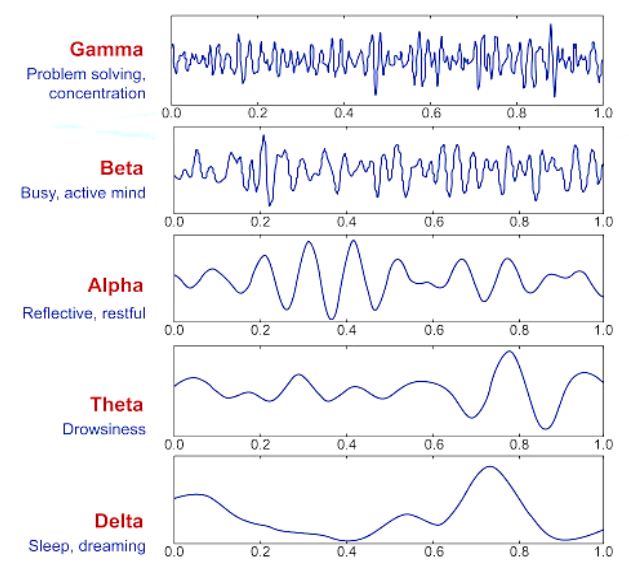

Figure 2. Beta, alpha, theta, and delta bands and gamma waves are the dominant frequencies of brain wave samples.
The alpha, beta, gamma, theta, and delta waves depicted in Figure 2 are the common EEG signals that can be extracted using an EEG sensor. An EEG signal is a type of brain activity that is measured using electrodes on the scalp that read tiny electric impulses [11], [12]. After that, a low pass filter and a high pass filter are used to amplify and filter the signal [13]. The common mode interference signal such as noise is removed by using a differential amplifier. The electrical signal generated by brain activity has a peak to peak voltage of 20-150 A and a frequency of $0.5-60 \mathrm{~Hz}$. The electrodes are positioned according to the 10-20 standard system, which is widely used across the world. The signal is amplified and filtered before being transformed to digital format by an ADC with highresolution and sent into the EEGLAB program for further handling [14].

Several studies have been conducted to see if EEG signals can be manipulated to regulate a variety of gadgets and appliances [15], [16]. The authors in [17] introduced a method to interpret human thoughts using EEG signals and LabView. The EEG signals are processed by using a wireless EEG amplifier and then the indicators are analysed in LabView to uncover the characteristics to define the human thinking. Machine learning is carried out, and the method allows the machine to learn from the training data and in turn predict future data.

The authors in [18], [19] examines eye blinks of a test subject as well as detecting their brain signals to behave as a conduit among a set of options indicated in the display where the user can select and command electrical appliances, wheelchair, and even a computer with no reliance on others. In another effort, [20] proposed an EEG analysis tools for emotion characterization using mobile robot for autism patients. Basically, a laser sensor is equipped on the robot to identify and track the children's location. A computer is used for processing brain signals and to set up regulations for the interaction. The robotic implementation allows two modes of interactions which are follower mode and dog mode, depends on level of interaction with the subject. Throughout the interaction session between the robot and the subject, the signals from subject's brain are captured by the EEG sensor and will be analysed by the computer.

Tanaka in [36] discussed his research towards an EEGbased control system for an electric wheelchair. The following statement specified the evaluation criterion: 


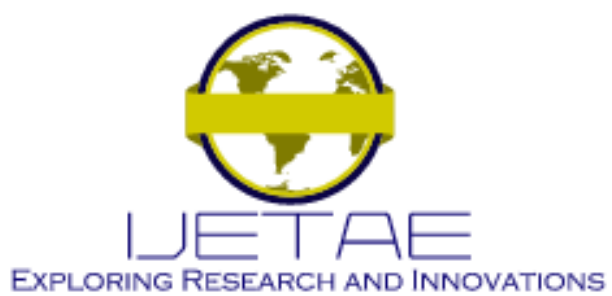

International Journal of Emerging Technology and Advanced Engineering

Website: www.ijetae.com (E-ISSN 2250-2459, Scopus Indexed, ISO 9001:2008 Certified Journal, Volume 11, Issue 10, October 2021)

"The electric wheelchair is able to reach the target when the number of wrong direction decisions is $\leq 1$ and the number of correct direction decisions is 3." The average success rate achieved was around $80 \%$ after 20 control trials with 6 participants.

The author in [21] developed an electrical appliance controller using the user's number of eye blink and attention level. The system has 2 controlling modes with 4 different attention readings. The system can turn on or off lights, fans, televisions, and buzzers in the first mode. The second mode enables the user to additionally regulate the volume and also change the channel of the television. Another similar research by [22] uses BCI to create a wireless interaction between a brain and a computer in order to control or run peripheral equipments. The proposed system controls home appliances using the attention brain signal level which is read by the noninvasive NeuroSky EEG headset. The user must achieve a mental focus state, which happens when the brain is having strong intensity and focused yet steady mental activity, on a scale of 1 to 100 .

\section{THE PROPOSED METHOD}

To get a clear picture of how this concept is intended to be applied, Figure 3 demonstrates a sample use case of the proposed system by a bedridden patient. By wearing the EEG headset, the patient can easily switch on/off any electrical appliance that is connected to the power socket prototype without even leaving the bed, just by focusing his mind and doing a preset mental task. The power socket consists of 4 individual sockets, and any one of them can be controlled independently.
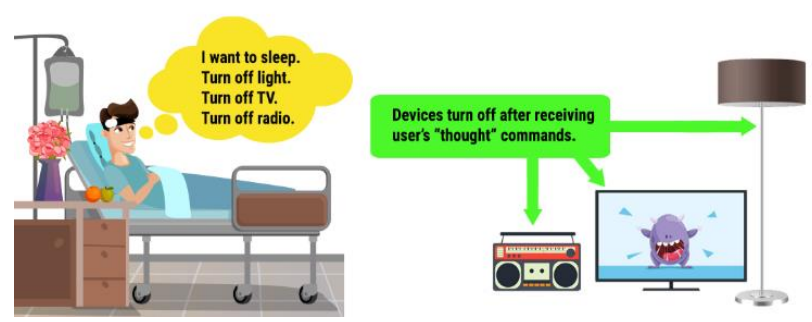

Figure 3. A sample use case of the system by a bedridden patient.
Raw EEG signals, which are the constantly fluctuating potential variance between the negative and the positive electrodes, are captured by the EEG headset from the user's brain, and the algorithm isolates individual brain waves such as low alpha, high alpha, low beta, high beta, delta, theta, low gamma, and mid gamma by applying a series of digital filters to the reported signal [23], and this concept is as illustrated as in Figure 4. Recent advances in signal processing and machine learning technologies have enabled computer systems to undertake further complex tasks, such as EEG data analysis. Delta (less than $4 \mathrm{~Hz}$ ), theta (4-8 $\mathrm{Hz}$ ), alpha $(8-13 \mathrm{~Hz})$, beta $(13-30 \mathrm{~Hz})$, and gamma (more than $30 \mathrm{~Hz}$ ) are some of the most common EEG subbands found in current research [24], [25].

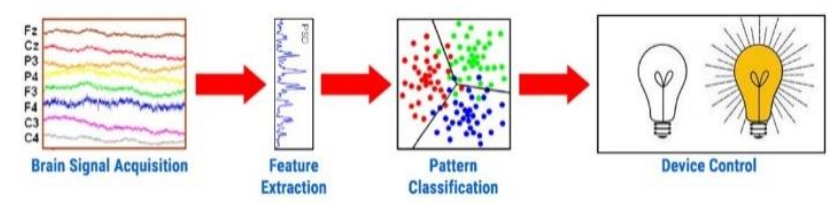

Figure 4. The software implementation concept.

Figure 5 below illustrates the block diagram of the suggested method. MindLink Neuro Sensor, a wearable dry EEG headset which can be observed in Figure 6, is linked wirelessly to the microcontroller via Bluetooth, and acts as a sensor to capture the input brain signals. An Arduino is used as the microcontroller that will process incoming data from the EEG headset and distinguish the brain wave signals received. The Arduino will in turn control the relays connected to the exterior power sockets and switch it on/off according to the algorithm.

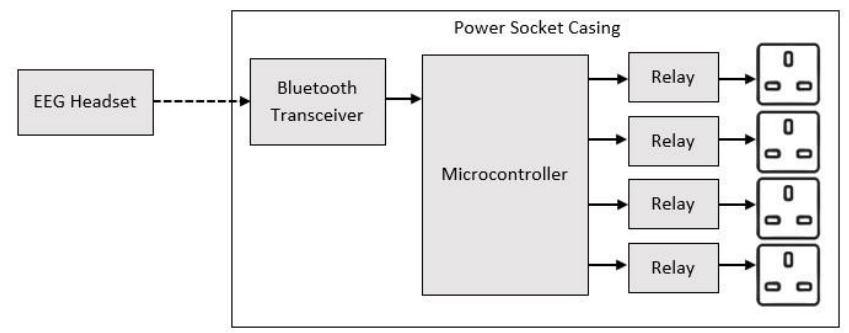

Figure 5. The hardware block diagram for the system. 


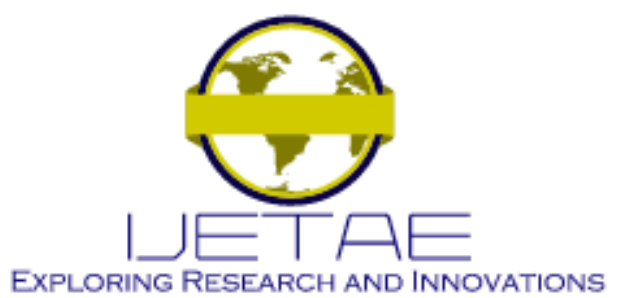

International Journal of Emerging Technology and Advanced Engineering

Website: www.ijetae.com (E-ISSN 2250-2459, Scopus Indexed, ISO 9001:2008 Certified Journal, Volume 11, Issue 10, October 2021)

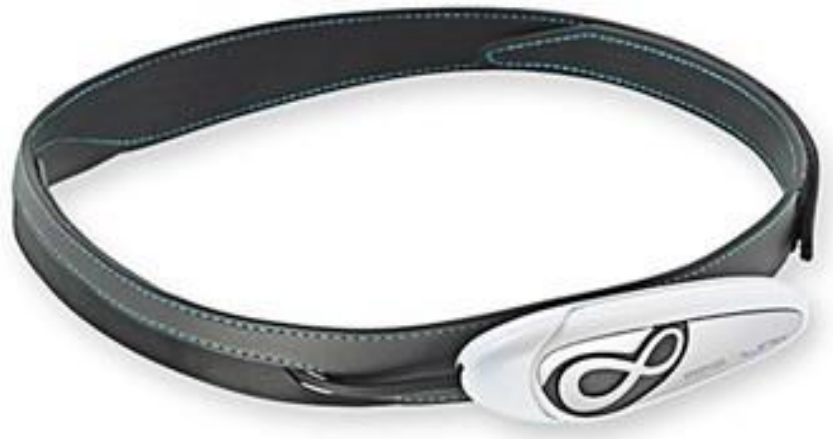

Figure 6. The MindLink EEG headset.

After the electronic hardware and software is integrated and tested successfully, the next step is to work on the industrial design to determine and define the power socket's form and features. The most important criterion for this casing is for it to be compact, but big enough to hide all the electronic circuitries underneath it. Figure 7 shows the technical drawing of the power socket casing. The drawing is modelled in $3 \mathrm{D}$ as illustrated in Figure 8. The 3D model is created using SolidWorks, and because creating models is faster than manually drawing lines, the technical drawing is thus produced automatically, and SolidWorks efficiently generates drawings from models with no errors. After further improvements are performed, the power socket is then 3D printed to turn the 3D drawing into an actual solid object which is then polished, and spray painted as illustrated in Figure 9.

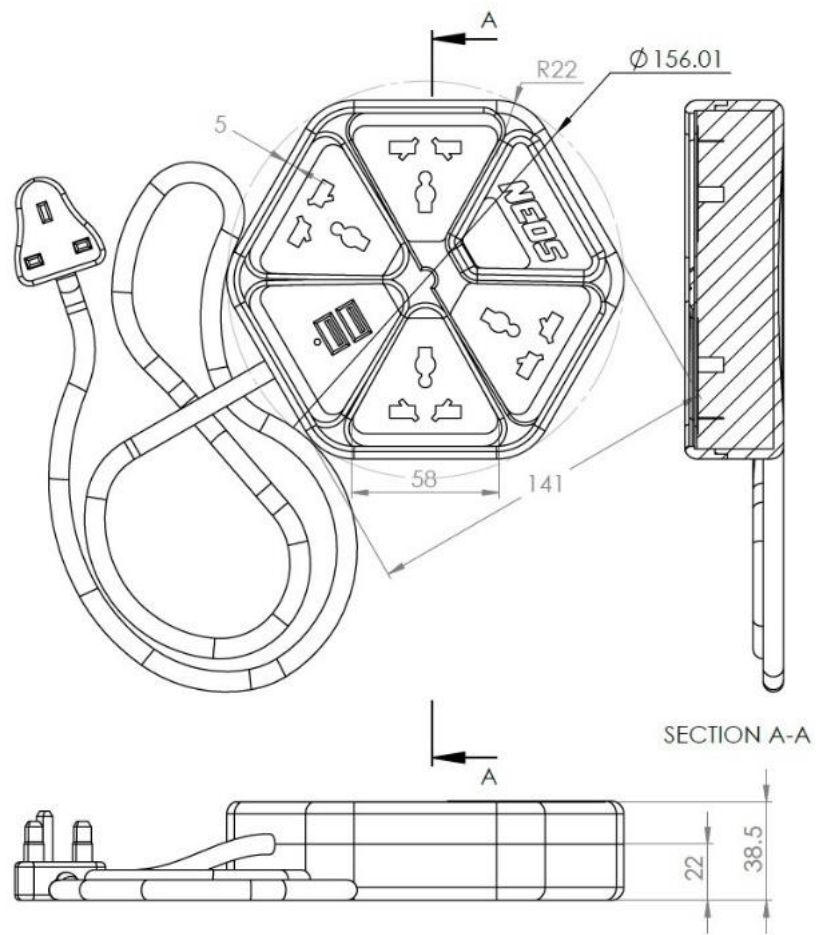

Figure 7.3D drawing of the prototype.

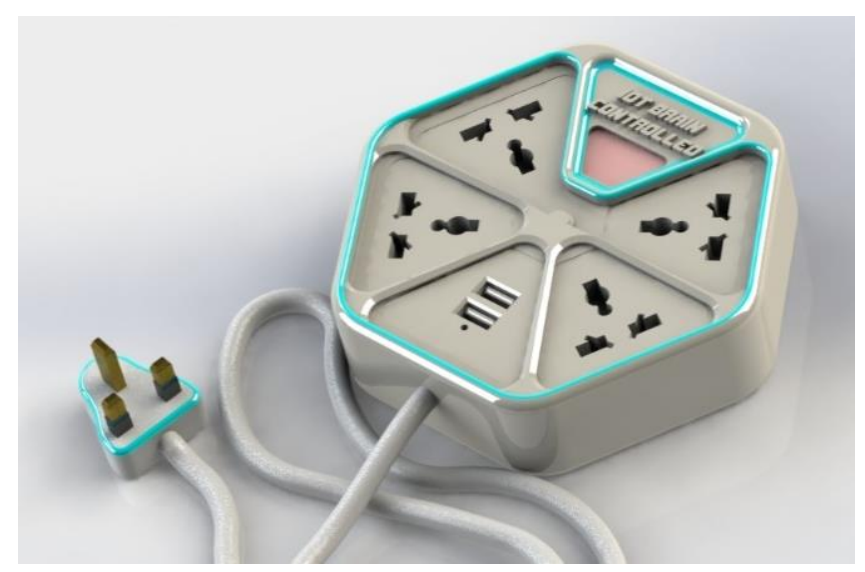

Figure 8. 3D render of the prototype. 


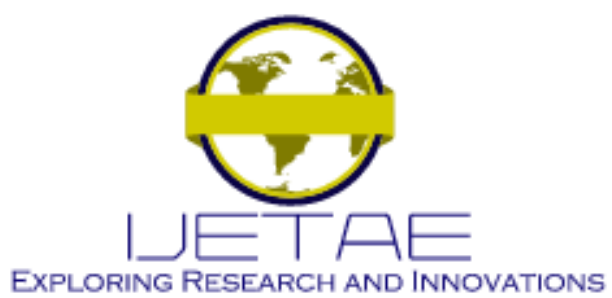

International Journal of Emerging Technology and Advanced Engineering

Website: www.ijetae.com (E-ISSN 2250-2459, Scopus Indexed, ISO 9001:2008 Certified Journal, Volume 11, Issue 10, October 2021)

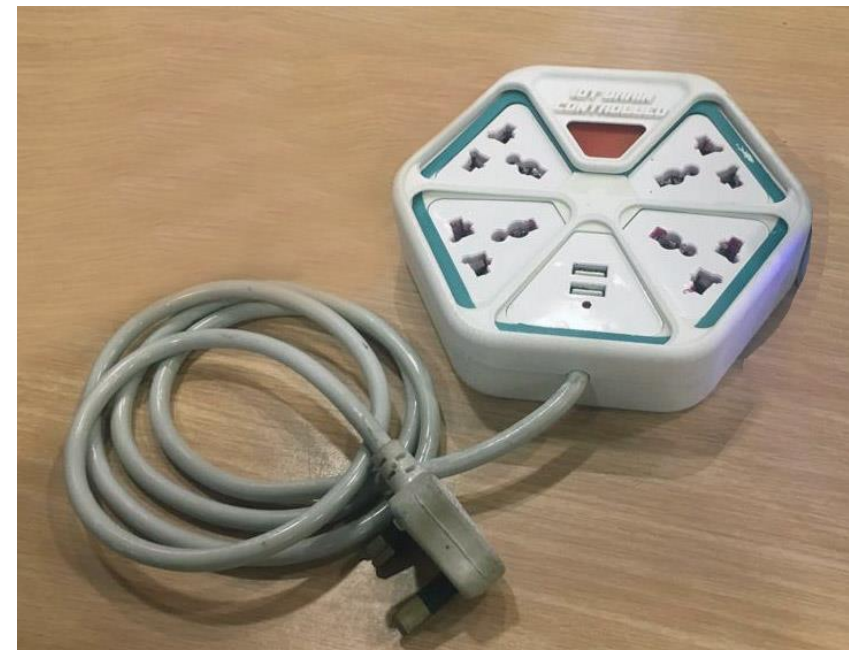

Figure 9. The 3D-printed prototype with the electronic system parts neatly hidden inside.

\section{RESULTS AND DISCUSSION}

When the EEG headset is switched on, it will blink its red LED to indicate that it is waiting to be paired with a master device, which is the Arduino microcontroller through the HC-05 Bluetooth module. The EEG headset will illuminate its blue LED after the connection is complete and the handshake process is completed. The headset is now ready to read brain signal data and the user can now wear the headset. To receive the correct sensor data, the user must make sure that the metal nodes are directly placed on the forehead while putting on the EEG headset as illustrated in Figure 10. When the EEG headset receives valid signals from the wearer's brain, it will emit two short beeps to indicate that it is correctly worn. The Fourier Transform (FT), WT, Common Spatial Pattern (CSP), and the logarithmic band power approach are all promising strategies for extracting information from raw EEG signals. The power spectrum density is mostly examined using FT techniques. The Fourier transform types include fast Fourier transform (FFT) and Discrete Fourier Transform (DFT). In comparison to DFT, FFT is commonly utilised in practical applications because of its simplicity and quick processing time [24].

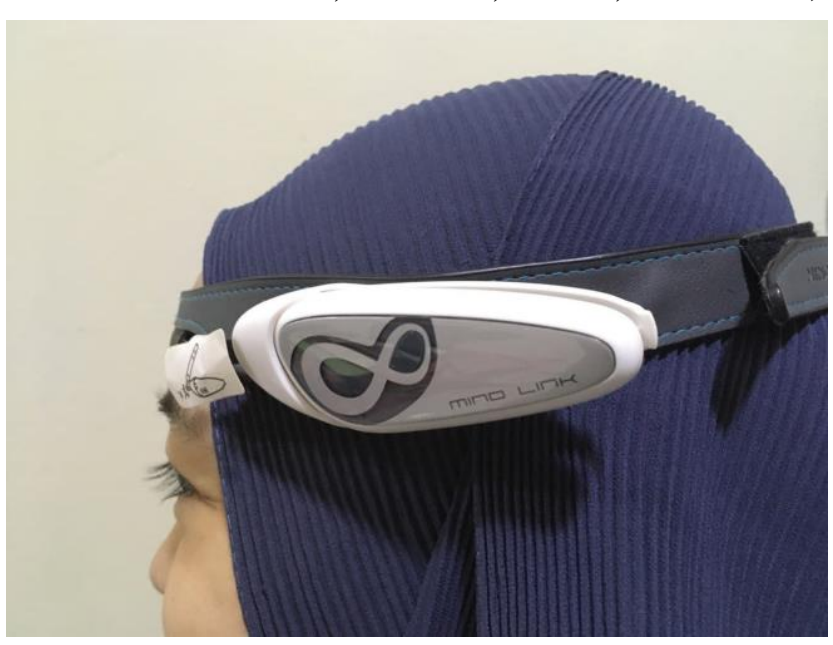

Figure 10. User is shown wearing the EEG headset properly, ensuring the metal nodes directly touch the forehead.

Once valid data is received from the EEG headset, the microcontroller will start separating each brain wave signals into the respective types, from alpha wave until theta wave, and the recorded graphs of brain waves while doing predetermined activities are observed. Figure 11 until Figure 15 depicts the graphs for alpha wave signals. Other brain wave signals such as the delta, theta, low beta, high beta, low gamma, and high gamma are also recorded although not shown in this paper. The brain waves are differentiated by their respective amplitude and nominal frequency.

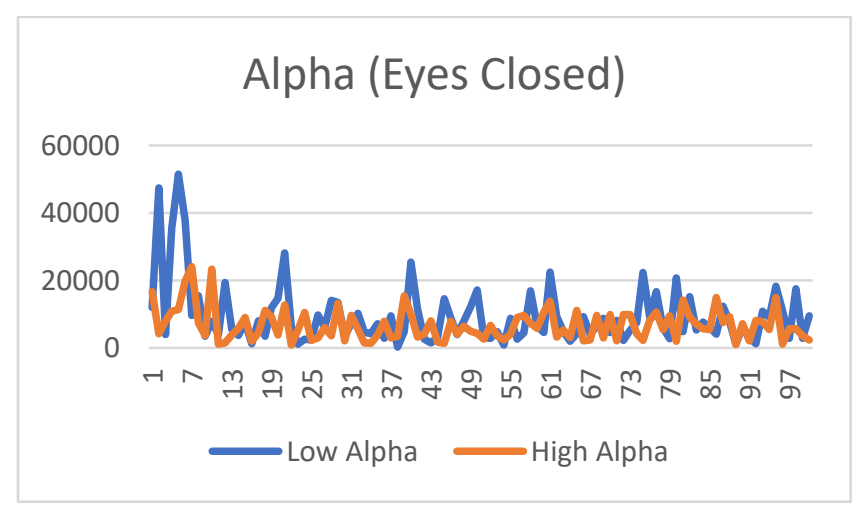

Figure 11. Alpha wave graph when eyes is closed. 


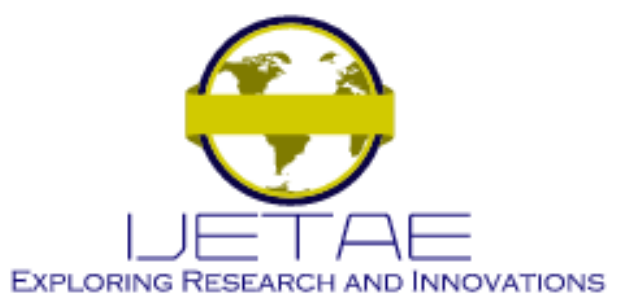

International Journal of Emerging Technology and Advanced Engineering

Website: www.ijetae.com (E-ISSN 2250-2459, Scopus Indexed, ISO 9001:2008 Certified Journal, Volume 11, Issue 10, October 2021)

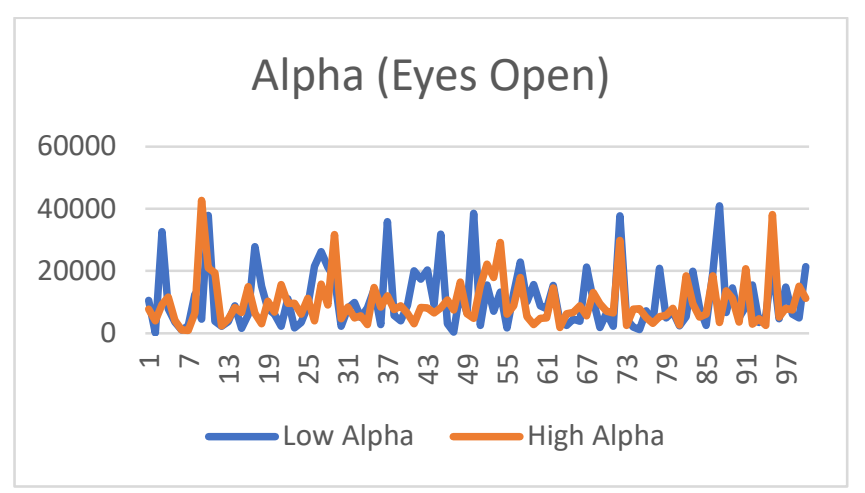

Figure 12. Alpha wave graph when eyes is open.

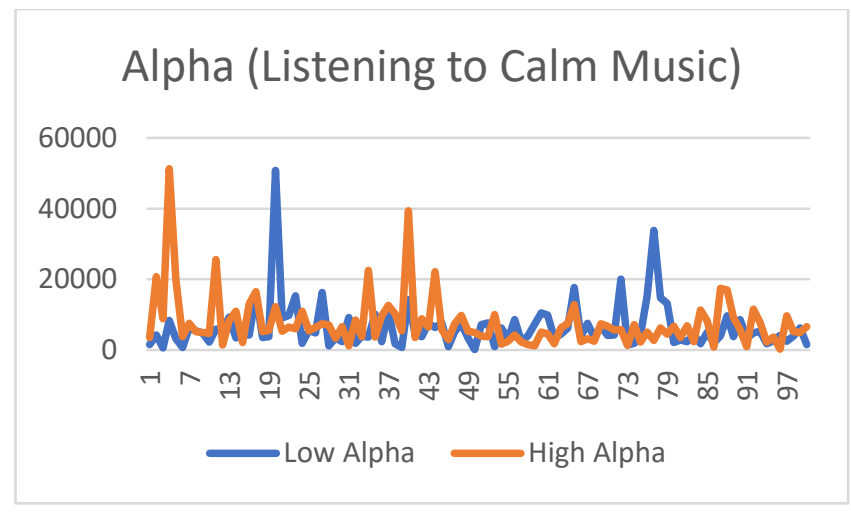

Figure 13. Alpha wave graph when listening to calm music.

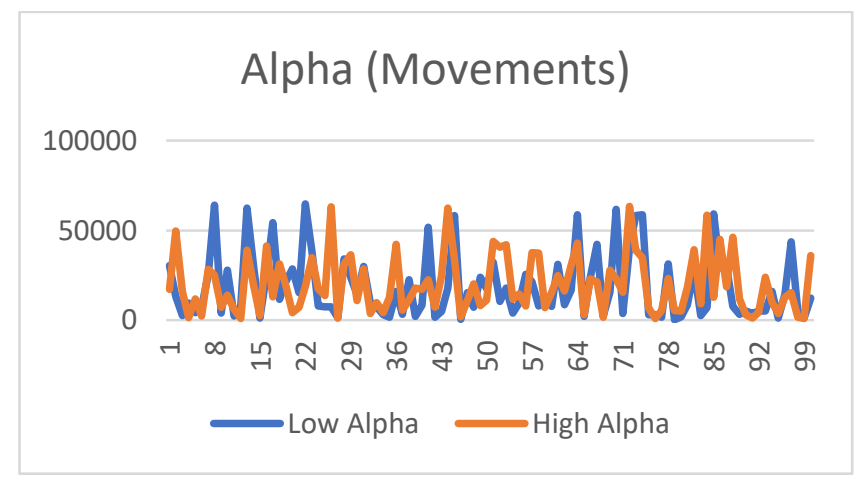

Figure 14. Alpha wave graph when making body movements.

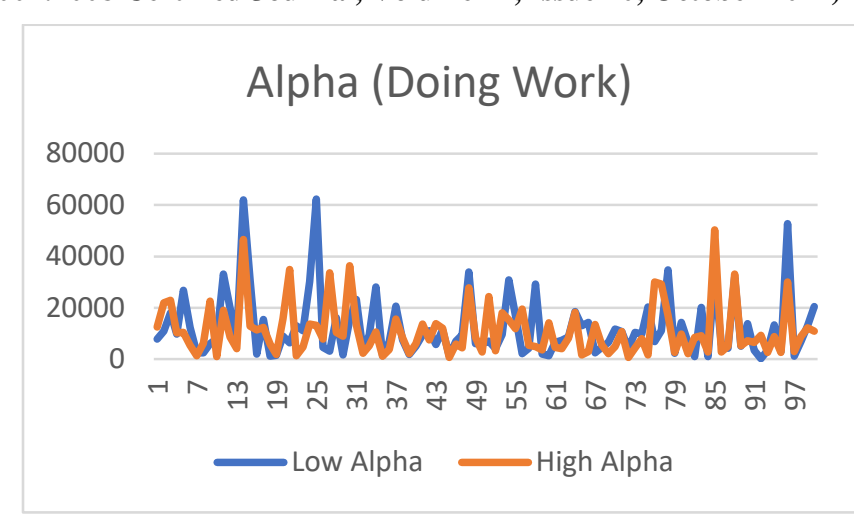

Figure 15. Alpha wave graph when doing work.

Based on the observation of the brain waves and the respective behaviours of the test subjects, the amplitudes and frequencies of different brain wave patterns can be discriminated, and the amount of activity or frequency of brain waves can then be classified. It is necessary to realize that brain waves are not the sole source of our own mental states or experiences as they are just a few of the visible manifestations of the brain's intricate operations that give us our sense of being, thinking, and perceiving. There are five commonly known brain waves, and the primary frequencies of human EEG waves, as well as their properties, which are presented in Table 1.

\section{Table 1.}

Brain waves and the associated mental state.

\begin{tabular}{|cl|}
\hline $\begin{array}{c}\text { Brain } \\
\text { Wave }\end{array}$ & \multicolumn{1}{c|}{$\begin{array}{c}\text { Active Mental State } \\
\text { and Condition }\end{array}$} \\
\hline Alpha & $\begin{array}{l}\text { Relaxed but not drowsy, calm, } \\
\text { conscious. }\end{array}$ \\
\hline Beta & $\begin{array}{l}\text { Relaxed yet focused, integrated, } \\
\text { alertness, agitation, anxious. }\end{array}$ \\
\hline Gamma & $\begin{array}{l}\text { Cognition, information } \\
\text { processing, concentration. }\end{array}$ \\
\hline Delta & $\begin{array}{l}\text { Unconscious, non-rapid eye } \\
\text { movement sleep, deep dreamless } \\
\text { sleep. }\end{array}$ \\
\hline Theta & $\begin{array}{l}\text { Intuitive, creative, memory recall, } \\
\text { fantasy, imagining, dreaming. }\end{array}$ \\
\hline
\end{tabular}




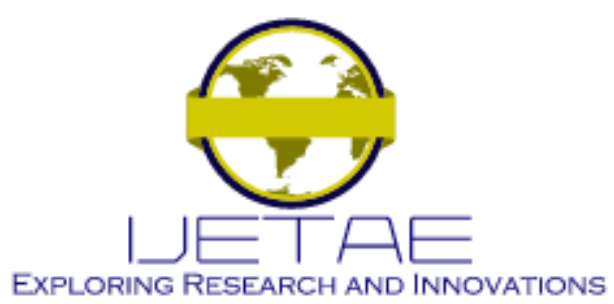

International Journal of Emerging Technology and Advanced Engineering

Website: www.ijetae.com (E-ISSN 2250-2459, Scopus Indexed, ISO 9001:2008 Certified Journal, Volume 11, Issue 10, October 2021)

From the various brain wave signals detected previously, two additional signals are derived, which is attention and meditation, as illustrated in Figure 16.

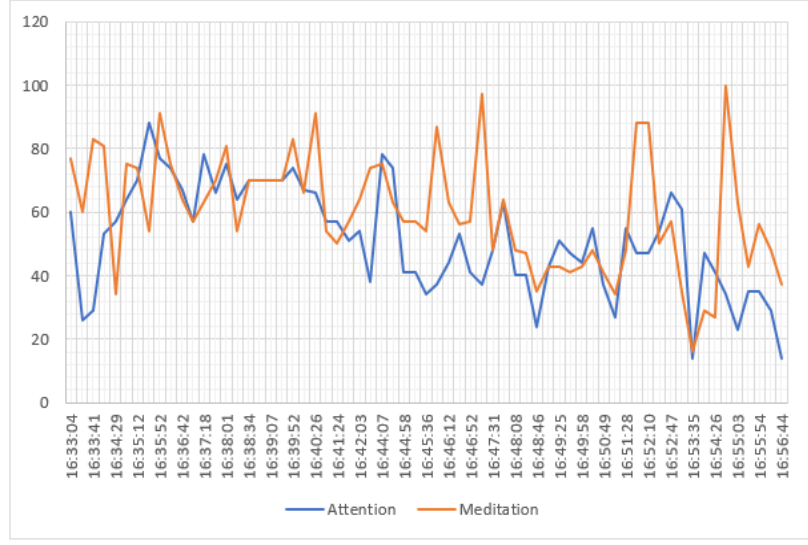

Figure 16. Attention and Meditation levels.

The intensity of a user's mental focus, such as that which happens during acute concentration or directed yet steady mental activity, is measured by attention. Distractions, stray thoughts, a lack of focus, or worry may all affect attention levels. If the attention level of a user is detected to be more than $80 \%$ for 3 seconds, the relay would be switched on and the respective electrical appliance will be switched on too. This state will be latched and maintained unless a cancelling trigger is detected.

Figure 17 shows the light is successfully turned on by using the thought command from the EEG headset. To switch it off, the user needs to maintain an attention level of $80 \%$ for 6 seconds. Note that the attention level of the user can be cancelled out by relaxing which in turn increases the meditation level. A preset combination of attention and meditation levels is configured to respond to the respective 4 power sockets in this project.

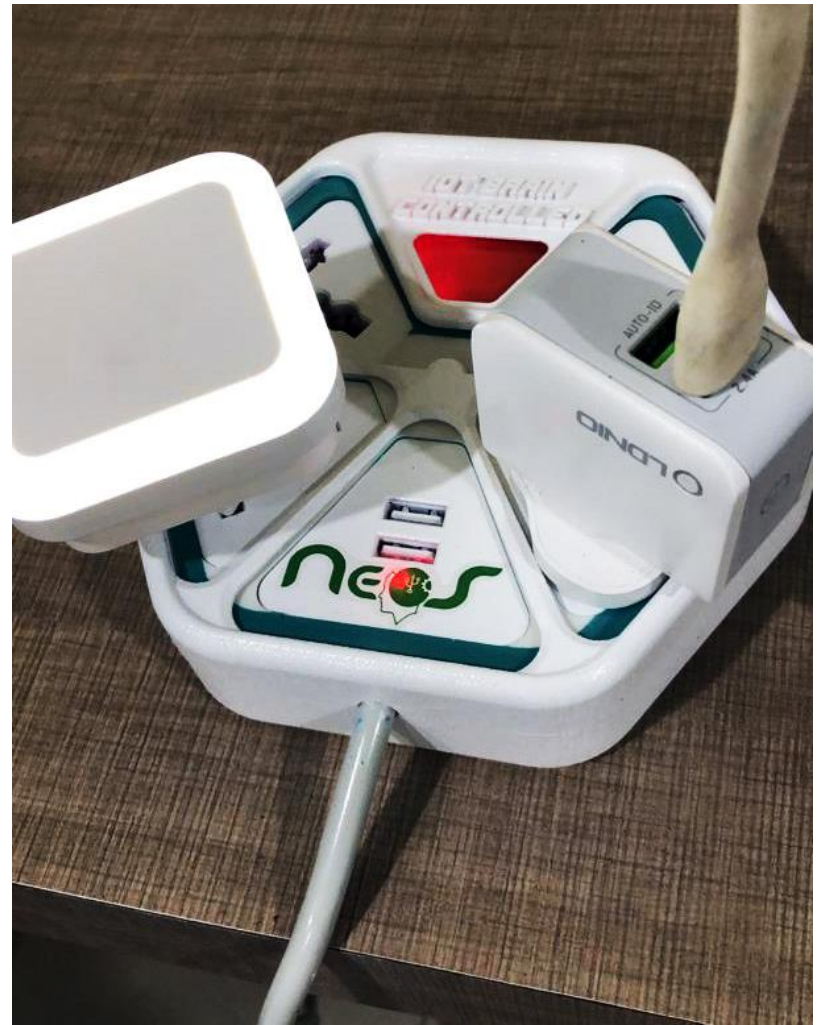

Figure 17. Light on socket 1 is turned on.

It is found that using the EEG headset to regulate a user's attention and meditation signal levels needed some practice before it can be done effortlessly. While the current preset values might be easy to achieve by some people, it can be tougher to other people, hence, proper calibration is proposed to tune the default values before use. A real-time brain wave graph visualizer as illustrated in Figure 18 can be used to aid the familiarization and practice of controlling a user's brain wave signal levels [26]. 


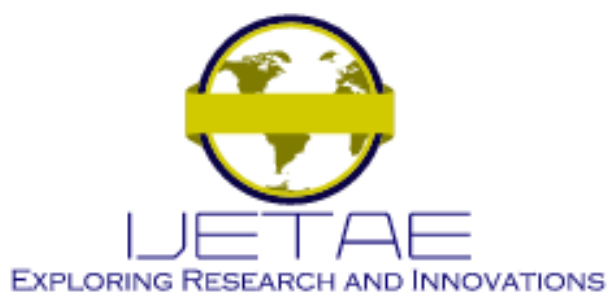

International Journal of Emerging Technology and Advanced Engineering Website: www.ijetae.com (E-ISSN 2250-2459, Scopus Indexed, ISO 9001:2008 Certified Journal, Volume 11, Issue 10, October 2021)

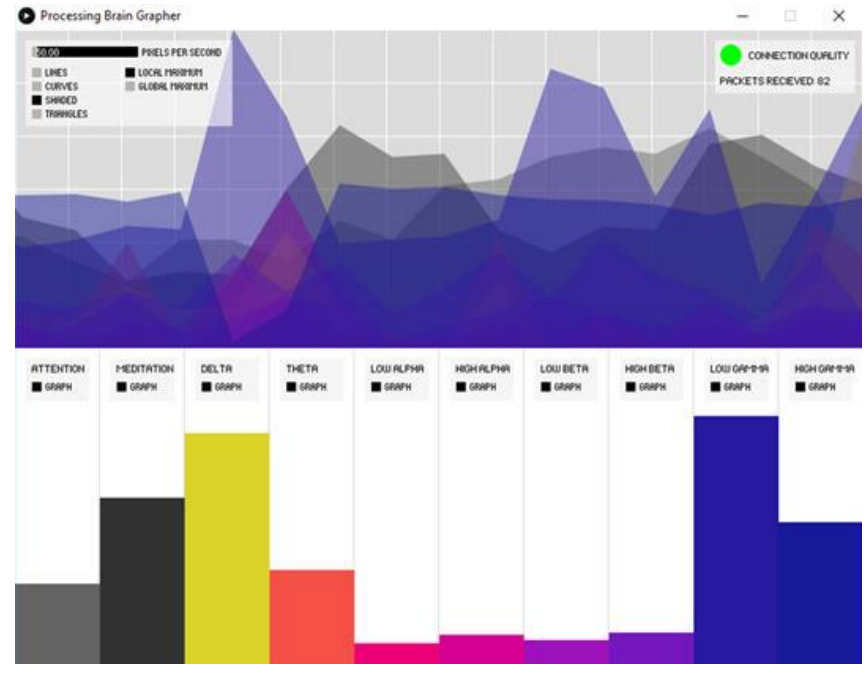

Figure 18. Processing Brain Graph visualizes real-time data sent by the EEG headset.

\section{CONCLUSION}

The development of an electrical appliance switching controller by using a wireless EEG headset is discussed in this paper. This system was designed to assist the elderly and disabled individuals to switch on and off electrical appliance independently. The proposed prototype comprises of a MindLink EEG sensor equipped with dry contact electrodes that can directly read real-time brain waves of a user. Based on the brain wave signals read, attention and meditation are determined to be the most suitable for this project and it is used to trigger the relay switching of the power socket. It is found that the response time to trigger the switching is slow as users require practice or need to undergo a passive training stage to control their brain wave signals efficiently. Because of personal idiosyncrasies and the non-stationary signal characteristics of the EEG, the system must additionally be calibrated using session-specific and user-specific data.

\section{Acknowledgements}

The authors would like to thank Universiti Teknikal Malaysia Melaka (UTeM) and MASH Construction Engineering Services Sdn. Bhd. for providing the support needed to complete the work herein via grant number MTUNC/2019/FTKEE-CACT/MC0016.

\section{REFERENCES}

[1] WHO, "World Report on Disability - Summary," World Report on Disability 2011, no. WHO/NMH/VIP/11.01, pp. 1-23, 2011.

[2] K. Tanaka, K. Matsunaga, and H. O. Wang, "Electroencephalogrambased control of an electric wheelchair," IEEE Transactions on Robotics, vol. 21, no. 4, pp. 762-766, Aug. 2005, doi: 10.1109/TRO.2004.842350.

[3] E. Perez-Valero, M. A. Lopez-Gordo, and M. A. Vaquero-Blasco, "An attention-driven videogame based on steady-state motion visual evoked potentials," Expert Systems, vol. 38, no. 4, p. e12682, Jun. 2021, doi: 10.1111/EXSY.12682.

[4] G. A. M. Vasiljevic and L. C. de Miranda, "A General Model for Electroencephalography-Controlled Brain-Computer Interface Games," Lecture Notes in Computer Science (including subseries Lecture Notes in Artificial Intelligence and Lecture Notes in Bioinformatics), vol. 12250 LNCS, pp. 174-189, Jul. 2020, doi: 10.1007/978-3-030-58802-1_13.

[5] C. L. Lin, M. Jung, Y. C. Wu, C. T. Lin, and H. C. She, "Brain dynamics of mathematical problem solving," Proceedings of the Annual International Conference of the IEEE Engineering in Medicine and Biology Society, EMBS, pp. 4768-4771, 2012, doi: 10.1109/EMBC.2012.6347033.

[6] J. J. Shih, D. J. Krusienski, and J. R. Wolpaw, "Brain-Computer Interfaces in Medicine," Mayo Clinic Proceedings, vol. 87, no. 3, p. 268, 2012, doi: 10.1016/J.MAYOCP.2011.12.008.

[7] P. M. Shende and V. S. Jabade, "Literature review of brain computer interface (BCI) using Electroencephalogram signal," 2015 International Conference on Pervasive Computing: Advance Communication Technology and Application for Society, ICPC 2015, Apr. 2015, doi: 10.1109/PERVASIVE.2015.7087109.

[8] A. A. Ghodake and S. D. Shelke, "Brain controlled home automation system," Proceedings of the 10th International Conference on Intelligent Systems and Control, ISCO 2016, Oct. 2016, doi: 10.1109/ISCO.2016.7727050.

[9] S. Belsare, M. Kale, P. Ghayal, A. Gogate, and S. Itkar, "Performance comparison of different EEG analysis techniques based on deep learning approaches," 2021 International Conference on Emerging Smart Computing and Informatics, ESCI 2021, pp. 490-493, Mar. 2021, doi: 10.1109/ESCI50559.2021.9396856.

[10] K. Q. Shen, X. P. Li, C. J. Ong, S. Y. Shao, and E. P. V. WilderSmith, "EEG-based mental fatigue measurement using multi-class support vector machines with confidence estimate," Clinical Neurophysiology, vol. 119, no. 7, pp. 1524-1533, Jul. 2008, doi: 10.1016/J.CLINPH.2008.03.012.

[11] S. G and L. EC, "Brain-computer interfaces using electrocorticographic signals," IEEE reviews in biomedical engineering, vol. 4, pp. 140-154, 2011, doi: 10.1109/RBME.2011.2172408.

[12] S. G, M. DJ, H. T, B. N, and W. JR, "BCI2000: a general-purpose brain-computer interface (BCI) system," IEEE transactions on biomedical engineering, vol. 51, no. 6, pp. 1034-1043, Jun. 2004, doi: 10.1109/TBME.2004.827072. 


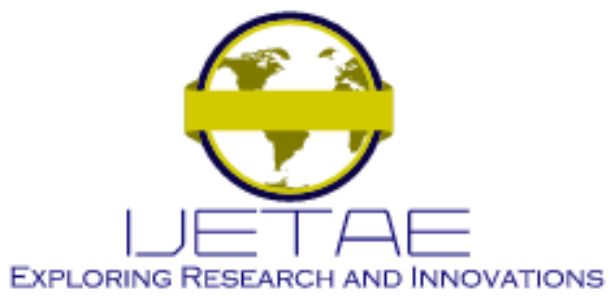

International Journal of Emerging Technology and Advanced Engineering

Website: www.ijetae.com (E-ISSN 2250-2459, Scopus Indexed, ISO 9001:2008 Certified Journal, Volume 11, Issue 10, October 2021)

[13] R. J. Barry and F. M. de Blasio, "Characterizing pink and white noise in the human electroencephalogram," Journal of Neural Engineering, vol. 18, no. 3, p. 034001, Mar. 2021, doi: 10.1088/1741-2552/ABE399.

[14] H. NJ et al., "Classifying EEG and ECoG signals without subject training for fast BCI implementation: comparison of nonparalyzed and completely paralyzed subjects," IEEE transactions on neural systems and rehabilitation engineering: a publication of the IEEE Engineering in Medicine and Biology Society, vol. 14, no. 2, pp. 183-186, Jun. 2006, doi: 10.1109/TNSRE.2006.875548.

[15] J. Khan, M. U. G. Khan, R. Iqbal, and O. Riaz, "Robust Multi-sensor Fusion for the Development of EEG Controlled Vehicle," IEEE Sensors Journal, pp. 1-1, May 2020, doi: 10.1109/JSEN.2020.2992714

[16] M. Nafea, A. B. Hisham, N. A. Abdul-Kadir, and F. K. Che Harun, "Brainwave-controlled system for smart home applications," 2nd International Conference on BioSignal Analysis, Processing and Systems, ICBAPS 2018, pp. 75-80, Nov. 2018, doi: 10.1109/ICBAPS.2018.8527397.

[17] N. Sulaiman, C. C. Hau, A. A. Hadi, M. Mustafa, and S. Jadin, "Interpretation of human thought using EEG signals and LabVIEW," Proceedings - 4th IEEE International Conference on Control System, Computing and Engineering, ICCSCE 2014, pp. 384-388, Mar. 2014, doi: 10.1109/ICCSCE.2014.7072749.

[18] A. O. Selvi, A. Ferikoğlu, D. Güzel, and E. Karagöz, "Göz Kirpmasi Tespiti İçin EEG İşaretleri Tabanli Beyin Bilgisayar Arayüzü Tasarimi ve Uygulamasi," 2nd International Conference on Computer Science and Engineering, UBMK 2017, pp. 544-548, Oct. 2017, doi: 10.1109/UBMK.2017.8093458.

[19] L. Rahman et al., "A low cost Human Computer Interface for Disabled People based on Eye Blink detection using Brain Signal," IEEE Region 10 Annual International Conference, Proceedings/TENCON, vol. 2019-October, pp. 1937-1941, Oct. 2019, doi: 10.1109/TENCON.2019.8929452.
[20] C. Goulart, J. Castillo, C. Valadão, T. Bastos, and E. Caldeira, "EEG analysis and mobile robot as tools for emotion characterization in autism," BMC Proceedings 2014 8:4, vol. 8, no. 4, pp. 1-2, Oct. 2014, doi: 10.1186/1753-6561-8-S4-P85.

[21] T. bin Nasir, M. A. M. Lalin, K. Niaz, and M. R. Karim, "Design and Implementation of EEG Based Home Appliance Control System," 2021 International Conference on Information and Communication Technology for Sustainable Development, ICICT4SD 2021 - Proceedings, pp. 445-449, Feb. 2021, doi: 10.1109/ICICT4SD50815.2021.9396982.

[22] A. A. Ghodake and S. D. Shelke, "Brain controlled home automation system," Proceedings of the 10th International Conference on Intelligent Systems and Control, ISCO 2016, Oct. 2016, doi: 10.1109/ISCO.2016.7727050.

[23] W. Jia and Y. Zeng, "EEG signals respond differently to idea generation, idea evolution and evaluation in a loosely controlled creativity experiment," Scientific Reports 2021 11:1, vol. 11, no. 1, pp. 1-20, Jan. 2021, doi: 10.1038/s41598-021-81655-0.

[24] M. Aljalal, S. Ibrahim, R. Djemal, and W. Ko, "Comprehensive review on brain-controlled mobile robots and robotic arms based on electroencephalography signals," Intelligent Service Robotics 2020 13:4, vol. 13, no. 4, pp. 539-563, Jun. 2020, doi: 10.1007/S11370020-00328-5.

[25] P. A. Abhang, B. W. Gawali, and S. C. Mehrotra, "Technological Basics of EEG Recording and Operation of Apparatus," Introduction to EEG- and Speech-Based Emotion Recognition, pp. 19-50, Jan. 2016, doi: 10.1016/B978-0-12-804490-2.00002-6.

[26] K. A. A. Aziz, A. F. Kadmin, M. A. AB. Aziz, N. Mohammed, and S. F. Abd Gani, "Design and Implementation of Neuro Based Switching System Control for Power Socket," International Journal of Recent Technology and Engineering, vol. 8, no. 4, pp. 79477951, Nov. 2019, doi: 10.35940/ijrte.D4218.118419. 